$\mathrm{L}(\mathrm{T}+\mathrm{O} 2.5 / 5 \mu \mathrm{g})$ and $0.140 \mathrm{~L}(\mathrm{~T}+\mathrm{O} 5 / 5 \mu \mathrm{g})$. SGRQ total scores improved by 5.1 (O $5 \mu \mathrm{g}), 5.7$ (T $2.5 \mu \mathrm{g}), 5.6$ (T $5 \mu \mathrm{g})$, $6.2(\mathrm{~T}+\mathrm{O} 2.5 / 5 \mu \mathrm{g})$ and 6.8 points $(\mathrm{T}+\mathrm{O} 5 / 5 \mu \mathrm{g})$; differences between $\mathrm{T}+\mathrm{O} 5 / 5 \mu \mathrm{g}$ and $\mathrm{O} 5 \mu \mathrm{g}$ and $\mathrm{T} 5 \mu \mathrm{g}$ were statistically significant $(\mathrm{p}$

Conclusions $\mathrm{T}+\mathrm{O} 5 / 5 \mu \mathrm{g}$ significantly improved lung function and provided symptomatic benefit over O $5 \mu \mathrm{g}$ and $\mathrm{T} 5 \mu \mathrm{g}$.

\section{P255 ONCE-DAILY TIOTROPIUM RESPIMAT $®$ ADD-ON TO AT LEAST ICS MAINTENANCE THERAPY REDUCES EXACERBATION RISK IN PATIENTS WITH UNCONTROLLED SYMPTOMATIC ASTHMA}

${ }^{1}$ DMG Halpin, ${ }^{2} \mathrm{P}$ Paggiaro, ${ }^{3} \mathrm{E}$ Bleecker, ${ }^{4} \mathrm{M}$ Engel, ${ }^{4} \mathrm{P}$ Moroni-Zentgraf, ${ }^{4} \mathrm{H}$ Schmidt, ${ }^{5} \mathrm{HAM}$ Kerstjens. 'Royal Devon and Exeter Hospital, Exeter, UK; ${ }^{2}$ University of Pisa, Pisa, Italy; ${ }^{3}$ Center for Genomics and Personalized Medicine, Wake Forest School of Medicine, Winston-Salem, USA; ${ }^{4}$ Boehringer Ingelheim Pharma GmbH and Co. KG, Biberach an Der Riss, Germany; ${ }^{5}$ University Medical Center Groningen, University of Groningen, Groningen, The Netherlands

\subsection{6/thoraxjnl-2014-206260.383}

Background A reduction in asthma exacerbation risk may provide improvements in clinical burden, patient experience and healthcare costs. In Phase III trials, once-daily tiotropium (delivered via the Respimat ${ }^{\circledR}$ SoftMist ${ }^{\mathrm{TM}}$ inhaler) added on to at least inhaled corticosteroids (ICS) improved lung function in patients with symptomatic asthma. We investigated exacerbation risk in each trial.

Methods Five Phase III, double-blind, placebo-controlled, parallel-group trials in patients with symptomatic asthma. Patients received tiotropium Respimat ${ }^{\circledR} 5 \mu$ g or placebo as add-on to at least ICS maintenance therapy (Table). Pre-planned co-primary or secondary end points were time to first severe exacerbation and time to any asthma worsening.

Results Mean baseline \% of predicted forced expiratory volume in 1 second, seven-question Asthma Control Questionnaire score and ICS dose $(\mu \mathrm{g})$ were: $56.0 \pm 13.1,2.6 \pm 0.7,1198 \pm 539$ (PrimoTinA-asthma $\left.{ }^{\circledR}\right) ; 75.1 \pm 11.5,2.2 \pm 0.5,660 \pm 213$ (MezzoTinAasthma $\left.{ }^{\circledR}\right) ; 77.7 \pm 11.9,2.1 \pm 0.4,381 \pm 78$ (GraziaTinAasthma ${ }^{\circledR}$ ). Tiotropium Respimat ${ }^{\circledR} 5 \mu \mathrm{g}$ reduced severe asthma exacerbation risk by at least $21 \%$ in all three severity cohorts (Table) and asthma worsening risk versus placebo in all trials, with a statistically significant reduction in the PrimoTinA-asthma ${ }^{\circledR}$ trial.

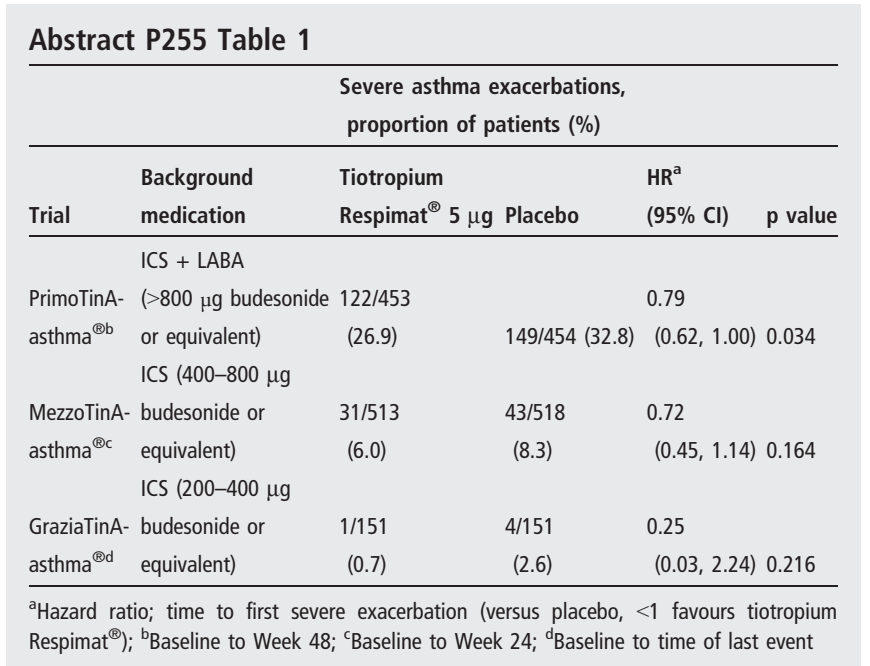

Conclusion Once-daily tiotropium Respimat ${ }^{\circledR} 5 \mu \mathrm{g}$ add-on to at least ICS maintenance therapy consistently reduced exacerbations across asthma severities and so may be a beneficial add-on option to reduce current and future exacerbation risk.

\section{P256 SAFETY OF ONCE-DAILY TIOTROPIUM AND OLODATEROL FIXED-DOSE COMBINATION VIA THE RESPIMAT IN CHRONIC OBSTRUCTIVE PULMONARY DISEASE IN TWO 1-YEAR STUDIES}

${ }^{1} \mathrm{R}$ Buhl, ${ }^{2} \mathrm{R}$ Abrahams, ${ }^{3} \mathrm{~L}$ Bjermer, ${ }^{4} \mathrm{E}$ Derom, ${ }^{5} \mathrm{M}$ Fležar, ${ }^{6} \mathrm{~J}$ Hébert, ${ }^{7} \mathrm{~A}$ Veale, ${ }^{8} \mathrm{~L}$ Grönke, ${ }^{9} \mathrm{~A}$ Hamilton, ${ }^{8} \mathrm{~K}$ Tetzlaff, ${ }^{10} \mathrm{~L}$ Korducki, ${ }^{11} \mathrm{H}$ Huisman, ${ }^{11} \mathrm{~S}$ Waitere-Wijker, ${ }^{12} \mathrm{~L} \mathrm{McG}$ arvey. ${ }^{1}$ Pulmonary Department, Mainz University Hospital, Mainz, Germany; ${ }^{2}$ Morgantown Pulmonary Associates, Morgantown, West Virginia, USA; ${ }^{3}$ Department of Respiratory Medicine and Allergology, Lund University, Lund, Sweden; ${ }^{4}$ Ghent University Hospital, Ghent, Belgium; ${ }^{5}$ Klinika Golnik, Golnik, Slovenia; ${ }^{6}$ Centre de Recherche Appliquée en Allergie de Québec (CRAAQ), Québec, Canada; 'Department of Respiratory Medicine, The Queen Elizabeth Hospital, Adelaide, Australia; ${ }^{8}$ Boehringer Ingelheim Pharma GmbH and Co. KG, Ingelheim, Germany; ${ }^{9}$ Boehringer Ingelheim, Burlington, Ontario, Canada; ${ }^{10}$ Boehringer Ingelheim Pharmaceuticals Inc., Ridgefield, Connecticut, USA; ${ }^{11}$ Boehringer Ingelheim B. V., Alkmaar, The Netherlands; ${ }^{12}$ Centre for Infection and Immunity, School of Medicine, Dentistry and Biomedical Sciences, Queen's University Belfast, Belfast, UK

\subsection{6/thoraxjn-2014-206260.384}

Introduction The fixed-dose combination (FDC) of tiotropium (T), a once-daily long-acting muscarinic antagonist, and olodaterol $(\mathrm{O})$, a once-daily long-acting $\beta_{2}$-agonist, is currently being evaluated in chronic obstructive pulmonary disease (COPD).

Two 52-week, Phase III replicate pivotal studies were conducted to assess the efficacy and safety of FDCs of T and $\mathrm{O}$ ( $\mathrm{T}$ $+\mathrm{O})$ delivered via Respimat ${ }^{\circledR}$ Soft Mist $^{\mathrm{TM}}$ inhaler in patients (pts) with GOLD Stage 2-4 COPD. Pooled safety data from the two studies are presented here.

Methods These were double-blind, randomised, parallel-group studies with 5 arms: O $5 \mu \mathrm{g}$, T $2.5 \mu \mathrm{g}$, T $5 \mu \mathrm{g}$, T+O 2.5/5 $\mu \mathrm{g}$, $\mathrm{T}+\mathrm{O} 5 / 5 \mu \mathrm{g}$. Key inclusion criteria were: age $\geq 40$ years, diagnosis of COPD, smoking history $>10$ pack-years. Pts with a history of asthma or significant disease other than COPD were excluded. Adverse events (AEs) were reported throughout the studies.

Results A total of 5162 pts were randomised and treated. In general, AEs, serious AEs and fatal AEs were balanced across treatment groups. In particular, frequencies of AEs in the cardiac disorders System Organ Class (SOC) and respiratory disorders SOC were similar.

\begin{tabular}{|c|c|c|c|c|c|}
\hline & \multicolumn{5}{|c|}{ Pts with $A E, \%$} \\
\hline & & & & $\mathrm{T}+0$ & $\mathrm{~T}+0$ \\
\hline & $05 \mu \mathrm{g}$ & $\mathrm{T} 2.5 \mu \mathrm{g}$ & T $5 \mu \mathrm{g}$ & $2.5 / 5 \mu \mathrm{g}$ & $5 / 5 \mu \mathrm{g}$ \\
\hline & $\mathrm{n}=1038$ & $\mathrm{n}=1032$ & $n=1033$ & $\mathrm{n}=1030$ & $n=1029$ \\
\hline Total AEs & 76.6 & 73.4 & 73.3 & 74.7 & 74.0 \\
\hline Serious AEs & 17.4 & 15.1 & 16.7 & 16.3 & 16.4 \\
\hline Fatal AEs & 1.3 & 1.2 & 1.6 & 1.4 & 1.7 \\
\hline Cardiac disorders* & 5.7 & 5.8 & 5.3 & 5.8 & 4.5 \\
\hline \multicolumn{6}{|l|}{ Respiratory, } \\
\hline \multicolumn{6}{|l|}{ thoracic and } \\
\hline mediastinal disorders* & 45.3 & 43.9 & 42.7 & 38.2 & 39.4 \\
\hline
\end{tabular}


Conclusions $\mathrm{T}+\mathrm{O}$ FDCs were safe and well tolerated. In comparison to the individual components, there was no notable increase in AEs with $\mathrm{T}+\mathrm{O}$ FDCs.

\section{P257 SUB-OPTIMAL INHALER TECHNIQUE IN PATIENTS AGED OVER 75 YEARS}

${ }^{1} S$ Vandermolen, ${ }^{2} \mathrm{~J}$ Berner, ${ }^{1} \mathrm{M}$ Almond, ${ }^{1} \mathrm{~F}$ Huwez. ${ }^{1}$ Southend University Hospital, Essex, UK: ${ }^{2}$ Barts and the London Medical School, London, UK

\subsection{6/thoraxjnl-2014-206260.385}

Introduction and objectives NICE guidelines highlight the importance of adequate inhaler technique to ensure sufficient drug delivery in asthma and C. O. P. D. Whilst adequate inhaler technique can be a problem for patients of any age, the delivery of inhaled medication continues to be a particular problem for elderly patients. Despite the existence of pressurised metereddose inhalers and breath-actuated inhalers, physical and cognitive impairment continues to make the use of hand-held inhalers difficult in the elderly. It is therefore likely that inhaler use in the elderly is suboptimal, regardless of device used.

Methods We assessed 50 consecutive patients aged over 75 years with C. O. P. D or asthma at our centre (mean age $78.24 \pm$ 7.32). All had inhaler therapy prescribed prior to examination. Two observers assessed inhaler technique against guidelines adapted from the National Asthma Council of Australia ${ }^{1}$ (see Table). Patients used either an Evohaler (pressurised metereddose inhaler) or Accuhaler (breath-actuated inhaler) according to their choice.

Results In the Evohaler group (25 patients), the average age was $78( \pm 5.5)$ with an average score of $6.6( \pm 1.81) / 10$. In the Accuhaler group (25 patients), average age was $77( \pm 6.4)$ with an average score of $7.2( \pm 2.0) / 10$. 'Crucial' steps to adequate inhaler technique were also assessed. ${ }^{2}$ The score in the Evohaler group was $4.4( \pm 1.2) / 6$, and in the Accuhaler group was 4.3 $( \pm 1.0) / 6$.

Conclusion This study shows that despite the availability of both Evohaler (pressurised metered-dose inhaler) and Accuhaler (breath-actuated inhaler) effective use by the elderly is still suboptimal. The very elderly need extra support when considering and prescribing inhalers. Whilst many centres have 'good inhaler technique' as a pillar of their COPD care bundle, it may be the case that specialist services, including the use of specialist devices, directed at the elderly may help to alleviate the problems of physical and cognitive impairment when using inhalers.

\begin{tabular}{lll}
\multicolumn{2}{l}{ Abstract } & P257 Table 1 \\
\hline Step & EVOHALER & ACCUHALER \\
\hline 1 & Remove cap & Open using thumb grip \\
2 & Hold inhaler upright and shake & Load dose by sliding lever until it clicks \\
3 & Breathe out & Breathe out \\
& Put mouthpiece between lips, & Put mouthpiece between lips, \\
4 & close lips to form seal & close lips to form seal \\
5 & Breathe in and press down & Breathe in steadily \\
6 & Continue to breathe in & Continue to breathe in \\
7 & Hold breath 10 secs & Hold breath 10 secs \\
8 & Remove inhaler & Remove inhaler \\
9 & Breathe out & Breathe out \\
10 & Replace cap & Close cover \\
\hline
\end{tabular}

\section{REFERENCES}

1 National Asthma Council Australia. Inhaler technique in adults with asthma or COPD. Melbourne: National Asthma Council Australia, 2008

2 Newman S. P. Inhaler treatment options in COPD. Eur Respir Rev 2005;14 (96):102-108

\section{P258 THE 24-HOUR LUNG FUNCTION PROFILE OF ONCE- DAILY TIOTROPIUM AND OLODATEROL FIXED-DOSE COMBINATION COMPARED WITH PLACEBO AND MONOTHERAPIES IN CHRONIC OBSTRUCTIVE PULMONARY DISEASE}

${ }^{1} \mathrm{E}$ Derom, ${ }^{2} \mathrm{~J}$ Westerman, ${ }^{3} \mathrm{~L}$ Grönke, ${ }^{4} \mathrm{~A}$ Hamilton, ${ }^{5} \mathrm{C} \mathrm{Li},{ }^{6} \mathrm{KM}$ Beeh. ${ }^{1}$ Ghent University Hospital, Ghent, Belgium; '2Pulmonary and Sleep Associates of Jasper, Jasper, Alabama, USA; ${ }^{3}$ Boehringer Ingelheim Pharma GmbH and Co. KG, Ingelheim, Germany; ${ }^{4}$ Boehringer Ingelheim, Burlington, Ontario, Canada; ${ }^{5}$ Boehringer Ingelheim Pharmaceuticals Inc, Ridgefield, Connecticut, USA; ${ }^{6}$ Insaf GmbH Institut Für Atemwegsforschung, Wiesbaden, Germany

\subsection{6/thoraxjnl-2014-206260.386}

Introduction Tiotropium (T), a once-daily long-acting muscarinic antagonist, is a well-established first-line maintenance treatment in chronic obstructive pulmonary disease (COPD). Olodaterol $(\mathrm{O})$ is a once-daily long-acting $\beta_{2}$-agonist, recently approved in several EU countries. This study investigated the 24-hour bronchodilator profile of once-daily fixed-dose combinations (FDCs) of $\mathrm{T}$ and $\mathrm{O}$ delivered via the Respimat ${ }^{\circledR}$ Soft Mist $^{\mathrm{TM}}$ inhaler in patients with Global initiative for chronic Obstructive Lung Disease 2-4 COPD.

Methods This double-blind, placebo-controlled, Phase III, incomplete crossover study randomised 219 patients to receive four of the following treatments for 6 weeks (with a 3-week washout period in between): placebo, O $5 \mu \mathrm{g}, \mathrm{T} 2.5 \mu \mathrm{g}$, T $5 \mu \mathrm{g}$, $\mathrm{T}+\mathrm{O}$ FDC $2.5 / 5 \mu \mathrm{g}, \mathrm{T}+\mathrm{O}$ FDC $5 / 5 \mu \mathrm{g}$. The primary end point was forced expiratory volume in 1 second $\left(\mathrm{FEV}_{1}\right)$ area under the curve from $0-24 \mathrm{~h}\left(\mathrm{AUC}_{0-24}\right)$ after 6 weeks. Secondary end points included additional spirometric parameters over $24 \mathrm{~h}$ and body plethysmography parameters in a sub-set of patients $(2: 30$ and 22:30 h post-dose).

Results The 24-hour time profiles for both FDCs were similar, with clear, consistent increases in $\mathrm{FEV}_{1}$ compared to placebo and monotherapies. For $\mathrm{FEV}_{1} \mathrm{AUC}_{0-24}$, both FDCs were significantly superior to placebo $(\mathrm{T}+\mathrm{O} 5 / 5 \mu \mathrm{g}$ : $0.280 \mathrm{~L}, \mathrm{p}<0.0001$; $\mathrm{T}+\mathrm{O} 2.5 /$ $5 \mu \mathrm{g}: 0.277 \mathrm{~L}, \mathrm{p}<0.0001)$ and monotherapies $(\mathrm{T}+\mathrm{O} 5 / 5 \mu \mathrm{g}$ : 0.110-0.127 L, p < 0.0001; T+O 2.5/5 $\mu \mathrm{g}: 0.107-0.124 \mathrm{~L}, \mathrm{p}<$ 0.0001). There were significantly greater increases in trough $\mathrm{FEV}_{1}$ with both FDCs compared to placebo (0.201-0.207 L, p < 0.0001) and monotherapies (T+O 5/5 $\mu \mathrm{g}$ : 0.079-0.107 L, p < 0.0001; T+O 2.5/5 $\mu \mathrm{g}: 0.073-0.101 \mathrm{~L}, \mathrm{p}<0.0001)$. In the body plethysmography sub-study, both FDC doses separated from

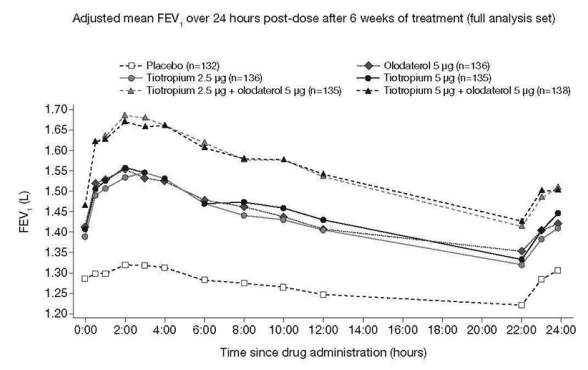

Abstract P258 Figure 1 Adjusted mean Fev 1 over $24 \mathrm{~h}$ post dose after 6 weeks of treatment (full analysis set) 